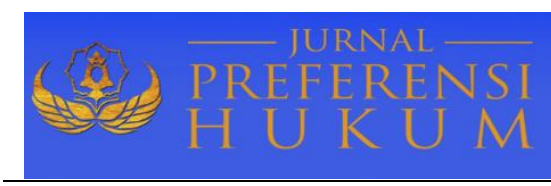

Jurnal Preferensi Hukum | ISSN: 2746-5039

Vol. 2, No. 1 -Februari 2021, Hal. 83-87| Available online at https://www.ejournal.warmadewa.ac.id/index.php/juprehum

DOI: https://doi.org/10.22225/jph.2.1.2799.83-87

\title{
PENGATURAN HUBUNGAN MENYIMPANG DI LUAR PERKAWINAN BAGI LESBIAN DAN GAY DALAM PERSPEKTIF HUKUM HINDU
}

\author{
I Kadek Grendy Bhineka, I Nyoman Putu Budiartha, Ni Made Puspasutari Ujianti \\ Fakultas Hukum Universitas Warmadewa, Denpasar-Bali, Indonesia \\ gianitadewi01@gmail.com, Fhwjurnal@Gmail.Com, puspasutari@Gmail.Com
}

\begin{abstract}
Abstrak
Perkawinan merupakan suatu ikatan lahir dan batin antara seorang laki-laki dengan perempuan sebagai suami istri dengan maksud untuk membentuk suatu keluarga (rumah tangga) yang bahagia dan kekal berdasarkan Ketuhanan Yang Maha Esa. Manusia diciptakan untuk berpasangan laki-laki dengan perempuan guna untuk meneruskan garis keturunan, namun ada segolongan orang yang berperilaku menyukai sesama jenis dan ingin melegalkan perbuatan mereka hingga kejenjang pernikahan melalui hukum yang berlaku di negaranya. Hal ini tentu saja tidak dapat diterima sebagian orang yang kontra dengan perilaku pernikahan sesama jenis yang biasa disebut Lesbian, Gay, Bisexual dan Transgender selanjutnya disebut LGBT. Penelitian ini bertujuan untuk menjelaskan pengaturan hubungan menyimpang diluar perkawinan bagi LGBT dalam perspektif hukum hindu yang kedua mendeskripsikan perspektif Agama dalam menyikapi pelaku LGBT. Penelitian ini didesain menggunakan penelitian hukum normatif dengna pendekatan yuridis melalui metode hermenutika. Data yang digunakn adalah data sekunder dan primer yang dianalisis secara kualitatif. Hasil penelitian menunjukkan Agama hindu tidak ada satu sloka maupun upacara yang melegalitaskan bahwa gay dan lesbi bisa melakukan perkawinan atau hubungan artinya tidak dibenarkan untuk menikah lebih-lebih dengan upacara suci, puja mantra $V e d a$, yang kedua tidak boleh mengucilkan atau mendiskriminasikan melainkan memberikan edukasi agar memperlakukan pelaku gay dan lesbian itu secara manusiawi, harus memberikan perlindungan atau mengedukasi pelaku apakah dia ditampung disuatu tempat kemudian diberikan pengarahan atau penyuluhan sehingga pelaku sadar mengenai perilaku perbuatan LGBT.
\end{abstract}

Kata kunci: Gay; Hubungan Menyimpang; Perspektif Hukum Hindu.

\begin{abstract}
Marriage is a physical and mental bond between a man and a woman as husband and wife with the aim of forming a happy and eternal family (household) based on the One Godhead. Humans were created to pair men with women in order to continue the lineage, but there are a group of people who behave like the same sex and want to legalize their actions up to the level of marriage through the laws in force in their country. This of course cannot be accepted by some people who contradict same-sex marriage behavior which is commonly referred to as Lesbian, Gay, Bisexual and Transgender, hereinafter referred to as LGBT. This study aims to explain the arrangement of deviant relationships outside of marriage for LGBT people in the perspective of Hindu law. The second one describes the religious perspective in dealing with LGBT perpetrators. This research is designed to use normative legal research with a juridical approach through the hermenutic method. The data used are secondary and primary data which are analyzed qualitatively. The results show Hinduism, there is no single verse or ceremony which legalizes that gay and lesbian can have a marriage or relationship, meaning that it is not allowed to marry, especially with a sacred ceremony, Vedic mantra puja, the second one should not isolate or discriminate but provide education to treat Humanly, gay and lesbian perpetrators must provide protection or educate the perpetrator whether he is accommodated in a place and then given direction or counseling so that the perpetrator is aware of LGBT behavior.
\end{abstract}

Keywords: Gay; Deviant Relationships; Hindu Legal Perspective

\section{PENDAHULUAN}

Gambaran kebesaran Tuhan adalah menciptakan segala makhluk di alam semesta selalu berpasangan. Laki-laki berpasangan dengan perempuan, demikian pula binatang diciptakan jantan berpasangan dengan betina (Satria, 2004). Melalui makhluk yang berpasangan itu, Tuhan memperlihatkan bagaimana kebesaranNya mengembang biakkan keturunan hingga makhluk hidup pun bertambah banyak dan besebaran di segala penjuru bumi. Sesuai fitrahnya bahwa pasangan laki-laki adalah perempuan dan perempuan denganlaki-laki. Namun ada segolongan orang yang berperilaku menyukai sesama jenis dan ingin melegalkan perbuatan mereka hingga kejenjang pernikahan melalui hukum yang 
berlaku dinegaranya. Hal ini tidak dapat diterima sebagian orang yang kontra dengan perilaku penyuka sesama jenis yang biasa disebut Lesbian, Gay, Bisexual dan Transgender selanjutnya disebut LGBT.

Kelompok yang kontra LGBT menganggap bahwa melegalkan sesuatu yang tak sesuai nalar sehat dan naluri kemanusiaan itu semata hanya ilusi yang dibuat-buat manusia dan merupakan sebuah penyimpangan terhadap keagamaan, sementara kelompok pro LGBT merasa adanya pengekangan dan penindasan hak-hak mereka sebagai warga negara. Perilaku LGBT juga terjadi di Bali yang menghebohkan dengan berlangsungnya pernikahan sejenis di kawasan Ubud, Gianyar, Bali.

Ulah pasangan beda warga negara ini membuat Gubernur Bali naik pitam. Gubernur Bali melarang keras pernikahan sesama jenis. Apalagi bawa agama Hindu sangat dilarang itu, karena itu kita mesti tegur, apapun alasannya pernikahan sejenis dilarang di manapun itu tidak boleh menurut Hindu.

Dalam kamus Besar Bahasa Indonesia Lesbian adalah sebagai wanita yang mencintai atau merasakan rangasangan seksual sesama jenisnya (Kamus Besar Bahasa Indonesia: 2002). Hukum sebagai norma mempunyai ciri kekhususan, yaitu hendak melindungi, mengatur dan memberikan keseimbangan dalam menjaga kepentingan para pihak (Djamali, 2008). Bali merupakan daerah pariwisata dianggap sebagian orang sebagai daerah yang bebas dan membolehkan kegiatan tersebut daripada daerah lainnya di Indonesia. Hal ini dibuktikan dengan digelarnya acara Grand Final Mister dan Miss Gay Dewata baru-baru ini, namun polisi membubarkan acara tersebut. Apabila melihat pada Undang-undang No. 16 Tahun 2016 tentang perkawinan pada Pasal I yang berbunyi Perkawinan ialah ikatan lahir bathin antara seorang pria dengan seorang wanita sebagai suami isteri dengan tujuan membentuk keluarga (rumah tangga) yang bahagia dan kekal berdasarkan Ketuhanan Yang Maha Esa.

Pasal terbaru Undang-undang perkawinan resmi disahkan dalam Undang- undang No.16 Tahun 2019 sebagai perubahan atas Undang-undang No. 1 Tahun 1974 tentang perkawinan yang di amatkan Mahkamah Konstitusi (MK). UU Perkawinan yang baru mengubah batas minimal laki-laki dan perempuan yang akan menikah minimal di usia 19 tahun. Berdasarkan pasal tersebut maka, hubungan seksual yang dianjurkan pada norma hukum itu adalah berdasarkan UU Perkawinan yakni hubungan yang terikat status perkawinan dan dilakukan oleh laki-laki dan perempuan. Ketentuan serupa juga menentang keberadaan LGBT mengenai isi kartu penduduk yang ditetapkan dalam Undang-Undang No. 23 Tahun 2006 tentang administrasi kependudukan dalam kegiatan penataan dan penertiban dalam penertiban dokumen dan data kependudukan melalui pendaftaran penduduk, pencatatan sipil, pengelolaan informasi administrasi kependudukan serta pendayagunaan hasilnya untuk pelayanan publik dan pembangunan sektor lain yang mengakui jenis kelamin hanya laki-laki dan perempuan.

Menurut hukum islam perkawinan LGBT tidak dapat dibenarkan (haram) karena bertentangan dengan pedoman hidup berkeluarga yang tercermin dalam wahyu transendental (al-Qur'an dan hadis), karena perkawinan LGBT mengancam eksistensi manusia yang bersifat esensial, yakni merusak keturunan, akal, jiwa dan kehormatan manusia (Rohmawati, 2016). Selanjutnya Mansur, (2017) hasil penelitiannya mengungkapkan bahwa Agama-agama di Indonesia, baik Islam, Kristen Katolik dan Protestan, Hindu, Buddha dan Konghucu sama-sama menolak perilaku homoseksual atau LGBT dan menolak pula pernikahan sesama jenis. Penelitian lain mengungkapkan bahwa Konstitusi Indonesia menempatkan Pancasila sebagai grundnorm dengan sila Ketuhanan Yang Maha Esa menjadi fondasi dan bintang pemandu pada Undang-undang Perkawinan Indonesia, yang intinya perkawinan harus antara pria dan wanita (heteroseksual) dengan tujuan membentuk keluarga (rumah tangga) (Sirait, 2017). Penlitian ini bertujuan untuk mengetahui pengaturan hubungan menyimpang di luar perkawinan bagi lesbian dan gay dalam perspektif Hukum Hindu yang kedua untuk mengetahui bagaimana pandangan agama hindu dalam menyikapi pelaku lesbian dan gay.

\section{METODE PENELITIAN}

Penelitian ini didesain dengan penelitian penelitian normatif. Penelitian hukum normatif adalah penelitian hukum doktrinal, juga disebut sebagai penelitian perpustakaan atau studi dokumen (Suratman \& Dillah, 2015). Sistem norma yang dimaksud adalah mengenal asas-asas, norma-norma, kaidah, peraturan perundang-undangan, putusan pengadilan, perjanjian serta doktrin. Data yang digunakan adalah sumber data hukum primer dan sekunder yang dianalisi secara kualitatif dan menerapkan pendekatan filsafat hukum.

\section{HASIL DAN PEMBAHASAN}




\section{Pengaturan Hubungan Menyimpang diLuar Perkawinan Bagi LGBT dalam Perspektif Hukum Hindu}

Berdasarkan Undang-Undang No. 16 Tahun 2016 tentang perkawinan Pasal 1 dijelaskan pengertian perkawinan yang berbunyi "Perkawinan ialah ikatan lahir bathin antara seorang pria dengan seorang wanita sebagai suami istri dengan tujuan membentuk keluarga (rumah tangga) yang bahagia dan kekal berdasarkan ketuhanan Yang Maha Esa". Pernikahan atau wiwaha dalam Agama Hindu adalah yadnya dan perbuatan dharma (Ningsih, 2020). Dalam adat Hindu di Bali merupakan upaya untuk mewujudkan hidup Grhasta Asrama, tugas pokoknya menurut lontar Agastya Parwa adalah mewujudkan suatu kehidupan yang disebut "Yatha sakti Kayika Dharma" yang artinya dengan kemampuan sendiri melaksanakan Dharma. Jadi seorang Grhasta harus benar-benar mampu mandiri mewujudkan dharma secara profesional haruslah dipersiapkan oleh seorang Hindu yang ingin menempuh jenjang perkawinan, atau Pawiwahan pernikahan adat menurut orang bali pada hakekatnya adalah upacara persaksian ke hadapan Tuhan Yang Maha Esa dan kepada masyarakat bahwa kedua orang yang bersangkutan telah mengikatkan diri sebagai suami-istri. Sarana Pawiwahan berupa Segehan cacahan warna lima, Api takep (api yang dibuat dari serabut kelapa), Tetabuhan (air tawar, tuak, arak), Padengan-dengan/pekata-kalaan, Pejati, Tikar dadakan (tikar kecil yang dibuat dari pandan), Pikulan (terdiri darcangkul, tebu, cabang kayu dadap yang ujungnya berisi periuk, bakul yang berisi uang), Bakul, Pepegatan terdiri dari dua buah cabang dadap yang dihubungkan dengan benang putih.

Menurut Pramitasari, (2017)Tujuan perkawinan dalam Agama Hindu adalah "terwujudnya keluarga yang berbahagia lahir bathin. Kebahagiaan ini ditunjang oleh unsur-unsur material dan non material. Pernikahan sebagai ekspresi akhir seorang individu dari suatu hubungan yang mendalam dimana dua individu bersumpah di depan umum didasarkan pada keinginan untuk menetapkan hubungan sepanjang hidupnya (Brehm, 1992). Pengaturan hubungan menyimpang diluar perkawinan bagi lesbian dan gay dalam perspektif Hukum Hindu Kamasutra menyebutkan, "Auparishtaka juga dilakukan oleh wanita-wanita liar dan para wanita penghibur, pelayan wanita, gadis-gadis pembantu rumah tangga yakni mereka yang tidak diperistri siapapun tetapi yang bermata pencaharian dengan memijat (Kama Sutra : 1992).

Perempuan tidak dibenarkan menodai seorang gadis, mereka dapat dipidana atau didenda. Pada sloka 369 dinyatakan, apabila seorang gadis menodai seorang gadis lain, akan didenda sebesar 200 pana dan membayar mas kawin dua kali lipat. Berdasarkan pernyataan tersebut dapat ditafsirkan bahwa seorang lesbi menodai seorang gadis lain maka dapat dikenakan sanksi. Dengan kata lain, seorang lesbi dilarang mendapatkan kesenangan seksual dengan gadis yang normal. Menurut Pramitasari, (2017) Mengidentifikasikannya sebagai sebadan sesama jenis (kelamin) atau cinta sesama jenis. Apabila itu dilakukan lebih-lebih dengan pemaksaan maka seorang lesbi dapat dipidana.

Dalam kitab suci Manava Dharmasastra tidak ditemukan pengaturan yang menyinggung keberadaan gay. Meski demikian aturan ini dapat juga diberlakukan terhadap mereka. Seorang lesbi ataupun gay dibenarkan mendapatkan kesenangan seksual dengan pasangan yang sama-sama homoseksual, tidak ada pengaturan secara khusus baik dalam undang-undang nasional yauitu No. 16 Tahun 2019 maupun di Manava Dharmasastra, akan tetapi yang diatur adalah mengenai pergaulan menyimpang pada kama sutra. Pada pandangan agama hindu tidak ada satu sloka maupun upacara yang melegalitaskan bahwa gay dan lesbi bisa melakukan perkawinan atau hubungan dan tidak dibenarkan untuk menikah lebih-lebih dengan upacara suci, puja mantra Veda.

Para Acarya berpendapat bahwa Auparistaka ini merupakan perbuatan seekor anjing dan manusia, karena merupakan perbuatan rendah dan bertentangan dengan aturan kitab suci (Menava Dharmasastra) dan karena manusia sendiri menderita dengan membiarkan linggamnya bersentuhan dengan mulut para waria dan wanita. Tetapi Watsyayana berkata bahwa aturan kitab suci tidak melarang mereka yang mengunjungi wanita penghibur dan hukum melarang pelaksanaan Auparishtaka dengan wanita yang bersuami saja (Pudja G DKK: 2002)

\section{Perspektif Hukum Hindu dalam Menyikapi Perilaku Lesbian dan Gay}

Penyebab terjadinya Lesbian dan gay adalah faktor biologis, pengaruh lingkungan yang tidak baik, pengalaman traumatis dan adanya keinginan untuk mencari kepuasan relasi homoseks (Kartono, 1989). Masyarakat melihat LGBT itu disebabkan terutama oleh faktor biologis atau genetik dan social (pengaruh lingkungan). Berdasarkan realita diketahui bahwa faktor biologis memiliki peran dalam membentuk seseorang untuk menjadi LGBT. Seseorang dapat menjadi LGBT karena keturunan atau 
karena kelainan genetik yang dimilikinya sejak lahir. Berbeda halnya dengan faktor sosial, masyarakat menganggap bahwa seseorang yang berada dilingkungan (sosial atau kerja) LGBT pada akhirnya akan mengikuti gaya hidup dan lama kelamaan bisa tertular menjadi LGBT. Sedangkan Gay yaitu Homoseksual, istilah ini Homo berasal dari bahasa Yunani yang berarti sama (Kartasapoetra \& Hartini, 1992). Masyarakat juga melihat bahwa seseorang dapat menjadi Lesbian dan Gay akibat trauma atau sakit hati.Trauma dalam arti pernah mengalami kekerasan (baik fisik maupun seksual) pada masa kecilnya atau sakit hati pada lawan jenis yang pernah berhubungan dengannya. Selain itu mereka menjadi Lesbian dan Gay karena faktor didikan keluarganya mendasari mereka menjadi seorang waria.

Ajaran Hindu tidak membenarkan pernikahan pria dengan pria (gay), wanita dengan wanita (lesbi). Penyimpangan yang dilakukan kaum Lesbian dan Gay memang bukan kejahatan akan tetapi hal itu tetap sebagai perbuatan dosa yang ditanggung oleh pribadi masing-masing. Filosofinya seseorang melangsungkan pernikahan itu untuk lahir ke dunia ini atas keinginan dari para leluhur yang akan reinkarnasi atas seijin Sang Hyang Widhi Wasa dan kemudian ketika ia sudah menjadi manusia ada semacam kewajiban manusia yang harus dipenuhi yaitu bersuami istri untuk meneruskan keturunan sekaligus kewajiban leluhur agar leluhurnya tidak dikenakan hukuman, sehingga karena konsepnya purusa dan pradana maka jika menikah tidak purusa pradana atau laki-laki dan perempuan tentu dilarang dan tidak diperbolehkan. Karena penyebutannya Purusa dan Pradana maka kelamin yang menyimpang atau hubungan yang menyimpang tentu tidak diperbolehkan untuk melangsungkan pernikahan karena yang di perbolehkan untuk menikah di sebut purusa dan pradana dan untuk pelaku Lesbian dan Gay tidak di perbolehkan karena tidak di akui dalam hukum Hindu artinya perkawinan yang menyimpang yang sama sama jenis atau jenisnya tidak jelas tidak di ajurkan atau di perbolehkan untuk melangsungkan pernikahan. Dalam konsep Hukum Hindu menyebutkan menikah itu adalah sebuah kewajiban, jika manusia tersebut tidak melangsungkan pernikahan akan dikenakan dosa terutama orang tuanya dan leluhurnya akan dikenakan hukuman.

Perilaku lesbian dan gay cenderung tidak sesuai dengan dharma kehidupan menurut ajaran Hindu. Individu Lesbian dan Gay menunjukan "Pengingkaran" dan tidak mensyukuri kelahirannya karena tidak memahami tujuan hidupnya dengan kodrat sebagai peria dan wanita. Umat Hindu dianjurkan untuk selalu berbuat dharma dan swadharmanya (kewajiban yang melekat sesuai potensi dirinya), seperti: mensyukuri keadaannya terlahir sebagai manusia itu adalah utama, secara biologi merujuk pada jenis kelamin yang dimilikinya, dan mengetahui tugas fungsinya.

Lesbian dan Gay cenderung menuruti nafsu birahi atau kepuasan seks saja sebagai penentu keberadaannya (eksistensi) dirinya terlahir didunia ini, sedangkan di dalam agama Hindu lebih ditekankan kepada pengendalian diri terutama pancaindrianya atau kama. Demikian pula penafsiran dangkal tentang Arjuna menjadi bencong bernama Brihanala sebagai pembenaran keberadaan waria. Sangat jelas, tujuan Arjuna menjadi Brihanala untuk tujuan mulia yaitu agar tidak terbongkar penyamaran para pandawa. Serupa kasusnya dengan kisah Shri Kandi yang lahir menjadi perempuan kemudian berubah menjadi laki-laki untuk tujuan mulia yaitu untuk mengakhiri hidup Bhisma yang agung. Tanpa kehadiran Shri Kandi dalam medan perang, maka Bhisma yang agung tak ada yang mampu mengalahkannya. Perubahan wujud Shri Kandi pun pada awalnya tidak direstui penguasa alam semesta, Mahadewa. Akan tetapi demi tujuan tegaknya Dharma, Shri Kandi direstui menjadi lelaki dalam beberapa waktu, hanya untuk mengalahkan Bhisma dalam medan perang.Penafsiran kisah-kisah dalam mitologi Hindu tidak dapat ditafsirkan, terlebih dijadikan pembenaran terhadap perilaku menyimpang, seperti homoseksual Lesbi dan Gay, di Hindu perkawnian yang disahkan itu adalah laki laki dan perempuan. Kalau yang sesama itu di Hindu apa lagi di Indonesia belum bisa karena peraturan dan undang undang perkawinan itu adalah laki-laki dan perempuan.

\section{SIMPULAN DAN SARAN}

\section{Simpulan}

Berdasarkan analisis data dapat diketahui bahwa Pernikahan sesama jenis tidak dibenarkan dalam ajaran Agama Hindu. Pustaka Suci Veda, menegaskan bahwa dalam Agama Hindu tidak ada aturan yang memperbolehkan perkawinan sejenis Dengan kata lain pelaku penyimpangan seks (homoseksual) tidak diberikan hak untuk mendapat upacara pernikahan atau upacara perkawinan dengan puja mantra Veda. Perkawinan (wiwaha) hanya dapat dilakukan antara seorang laki-laki dan seorang perempuan dengan tujuan membentuk keluarga yang sejahtera dan bahagia untuk 
memperoleh keturunan, yang kedua Pandangan Agama Hindu mengakui adanya pelaku Lesbian dan Gay secara tertulis diakui adanya penyimpangan tersebut tetapi tetap melarang karena dianggap tidak bermartabat dan tetap ada sangsi seperti yang telah tercantum pada kitab Kama Sutra dan Manawa Dharmasastra.

\section{Saran}

Adapun yang disarankan oleh peneliti adalah Bagi masyarakat tegas menolak pernikahan sesama jenis tetapi jangan mengucilkan atau mendiskriminasikan melainkan memberikan edukasi agar memperlakukan pelaku gay dan lesbian itu secara manusiawi. Terutama orang tua lebih memperhatikan pergaulan anaknya karena LGBT ini biasa menyerang/mempengaruhi semua orang lewat berbagai media, selanjutnya Bagi pemerintah harus memberikan perlindungan atau mengedukasi pelaku apakah dia ditampung disuatu tempat kemudian diberikan pengarahan atau penyuluhan diberikan terapi psikologis sehingga pelaku sadar mengenai perilaku perbuatan LGBT. Melebih bertindak tegas dan berani mengatakan bahwa hal tersebut salah dan dilarang di indonesia karena hal tersebut lebih banyak mengandung keburukan bila dibandingkan dengan kebaikan.

\section{DAFTAR PUSTAKA}

Brehm, S. S. (1992). Intimate Relationship.

Djamali, R. A. (2008). Pengantar Hukum Indonesia. Raja Grafindo.

Kartasapoetra, \& Hartini. (1992). Kamus Sosiologi dan Kependudukan. Bumi Aksara.

Kartono, K. (1989). Psikologi Abnormal dan Abnormalitas Seksual. Cv. Mandar Maju.

Mansur, S. (2017). Homoseksual dalam Perspektif Agama-Agama di Indonesia. Aqlania, 8(1), 21-60.

Ningsih, L. S. (2020). Upacara Pawiwahan dalam agama Hindu. Jurnal Widya Sastra Pendidikan Agama Hindu, Pramitasari, N. L. G. F. (2017). Eksisrensi Wanita dalam Manawa Dharmasastra. Jurnal Penelitian Agama Hindu, $1(1), 24-31$.

Rohmawati, R. (2016). Perkawinan Lesbian, Gay, Biseksual dan Transgender/Transeksual Perspektif Hukum Islam. Ahkam, 4(2), 305-326.

Satria, S. (2004). Komposisi Materi. Komposisi Materi, 20(1), 66-78.

Sirait, T. M. (2017). Menilik Akseptabilitas Perkawinan Sesama Jenis di dalam Konstitusi Indonesia. Jurnal Konstitusi, 14(3), 621-643.

Suratman, \& Dillah, H. P. (2015). Metode Penelitian Hukum. 